Aims The overall aim was to move towards a shared vision of person-centred culture that focused strongly on people's individual beliefs and values, processes and the care environment. Methods Transformational methods demonstrating the principles of practice development (McCormack et al., 2013) were used to create and define the person-centred vision and to explore and evaluate person-centred culture. The overall approach used the CIP principles - to be collaborative, inclusive and participative therefore the key group acted as facilitators for the wider hospice team. Evaluation methods included staff and patient stories and observations of care and environment. Facilitated events also took place to explore workplace culture, relationships and practices within designated teams.

Results Measuring culture change is challenging and often takes place over a longer period than the two-year time frame of facilitation and active learning with QMU. Observations and feedback do however show demonstrable change. External teams have commented on the cohesiveness of teams with less silo-working and a greater understanding of each other's purpose and values. The sessions to explore workplace culture also seem to have heightened self-awareness and instigated some changed behaviours in practice. More obvious and measurable changes have been to the physical environment which is much now more colourful and welcoming. This enhances an overall impression of culture shift and person-centredness.

Conclusion The person-centred processes that have been used in all aspects of the work have proved to be effective and will continue through active facilitation and integration within all areas of the hospice in the future.

\section{P-291 SHIFTING SANDS - USING EMANCIPATORY PRACTICE DEVELOPMENT TO HELP ENGAGE WITH CULTURE}

${ }^{1}$ Melanie Legg, ${ }^{1}$ Anne Cleary, ${ }^{2}$ Caroline Dickson, ${ }^{2}$ Brendan McCormack. ${ }^{1}$ Marie Curie, London, UK; ${ }^{2}$ Queen Margaret University, Edinburgh, UK

\subsection{6/bmjspcare-2017-hospice.316}

Background Culture is not about individuals but about the social contexts that influence the way people behave and the social norms that are accepted and expected (Manley et al., 2011). Culture is widely understood as how things are done around here' (Drennan, 1992). Anthony (1994) argues that corporate culture reflects what is espoused, what the organisation wants to portray rather than the actual culture that is experienced. Nursing practice is significantly impacted by the constantly evolving societal, environmental and organisational context in which nurses work (Keyko, 2014; McCormack et al., 2013). The dominant NHS approach in recent years has been described as 'pace-setter' (King's Fund, 2012), a command and control culture with little delegation or collaboration, which is primarily driven by top down targets (Riley, 2014). The present health care environment is paternalistic (Newton, 2000) and predominantly task orientated which can lead to fundamental care falling short (Shannon \& Peelo-Kilroe, 2012; Francis, 2010). Emancipatory practice development is the product of critical social theory (Shaw, 2013; Fairbrother et al., 2015), action orientated (McCormack et al., 1999) and transformational. It relies on the development and maintenance of critical and progressive clinical practice cultures which drive change and growth in health care practice (Manley et al., 2013; Fairbrother et al., 2015).

Aims Understand the perception of culture
Engage staff with their beliefs of self and culture. Methods Using creative emancipatory practice development methodologies to explore questions about culture in a less confrontational way.

Conclusion Practice development and person-centred care aim to establish workplace cultures that enable everyone to flourish (Manley et al., 2014). Working collaboratively and enabling staff to contribute to the future success of the organisation provides them with a voice and creating shared governance contributes to an atmosphere of respect for staff (Boyer, 2005).

\section{P-292 COLLABORATIVE WORKING IN HOSPICE ESTATES AND FACILITIES TEAMS AND THE CREATION OF INNOVATION}

${ }^{1,2}$ Kevin McGill, ${ }^{1,2}$ Lorraine Rickett. 'St Helena Hospice, Colchester, UK; ${ }^{2}$ St Elizabeth Hospice, Ipswich, UK

\subsection{6/bmjspcare-2017-hospice.317}

Background Estates and Facilities services play a key role in delivering a safe, secure and comfortable hospice environment for patients and visitors. There is growing evidence that working collaboratively can improve overall hospice care provision. In 2016, Hospice A agreed to share their Head of Estates and Facilities role for an interim period of six months at Hospice B. During this period both hospices used this collaborative opportunity to compare services, learn from each other and to improve estates and facilities services for patients and visitors.

Aim To explore, identify, and discuss aspects of Estates and Facilities at both hospices that could be identified as best practice. To implement good initiatives at both hospices so the physical environment can be made safer and more welcoming for patients and visitors. To work collaboratively and identify further projects for future collaboration.

Methods The information concerning best practice was identified through team meetings, interviews with staff, observational methods and review and comparison of operational procedures.

Results For Hospice A the following initiatives were adopted from current practices of Hospice B:

- Maintenance volunteers

- Weekly maintenance plan

- Monthly health and safety group

- Catering infection control improvements.

For Hospice $\mathrm{B}$ the following initiatives were adopted from Hospice A:

- Annual Health and Safety report to IOSH level 2

- Maintenance helpdesk

- Facilities administration volunteers

- Health and Safety awareness poster campaign.

The following areas were identified for future collaborative working:

- annual PLACE Audit

- Benchmarking health and safety performance

- Review of contractors and suppliers.

Conclusion Sharing knowledge and experience of estates and facilities teams at both hospices led to tangible, measurable benefits. The experience required both hospices to have a positive attitude towards change and be open to new ways of doing things. Both hospices have agreed to continue to work collaboratively and on current and future estates and facilities projects. 